This item was submitted to Loughborough's Research Repository by the author.

Items in Figshare are protected by copyright, with all rights reserved, unless otherwise indicated.

\title{
Hospital resilience to natural hazards: classification and performance of
} utilities

PLEASE CITE THE PUBLISHED VERSION

http://dx.doi.org/10.1108/DPM-03-2013-0057

PUBLISHER

(c) Emerald Group Publishing Ltd

VERSION

AM (Accepted Manuscript)

LICENCE

CC BY-NC-ND 4.0

\section{REPOSITORY RECORD}

Achour, Nebil, Masakatsu Miyajima, Federica Pascale, and Andrew D.F. Price. 2019. "Hospital Resilience to Natural Hazards: Classification and Performance of Utilities". figshare. https://hdl.handle.net/2134/14813. 
This item was submitted to Loughborough's Institutional Repository (https://dspace.lboro.ac.uk/) by the author and is made available under the following Creative Commons Licence conditions.

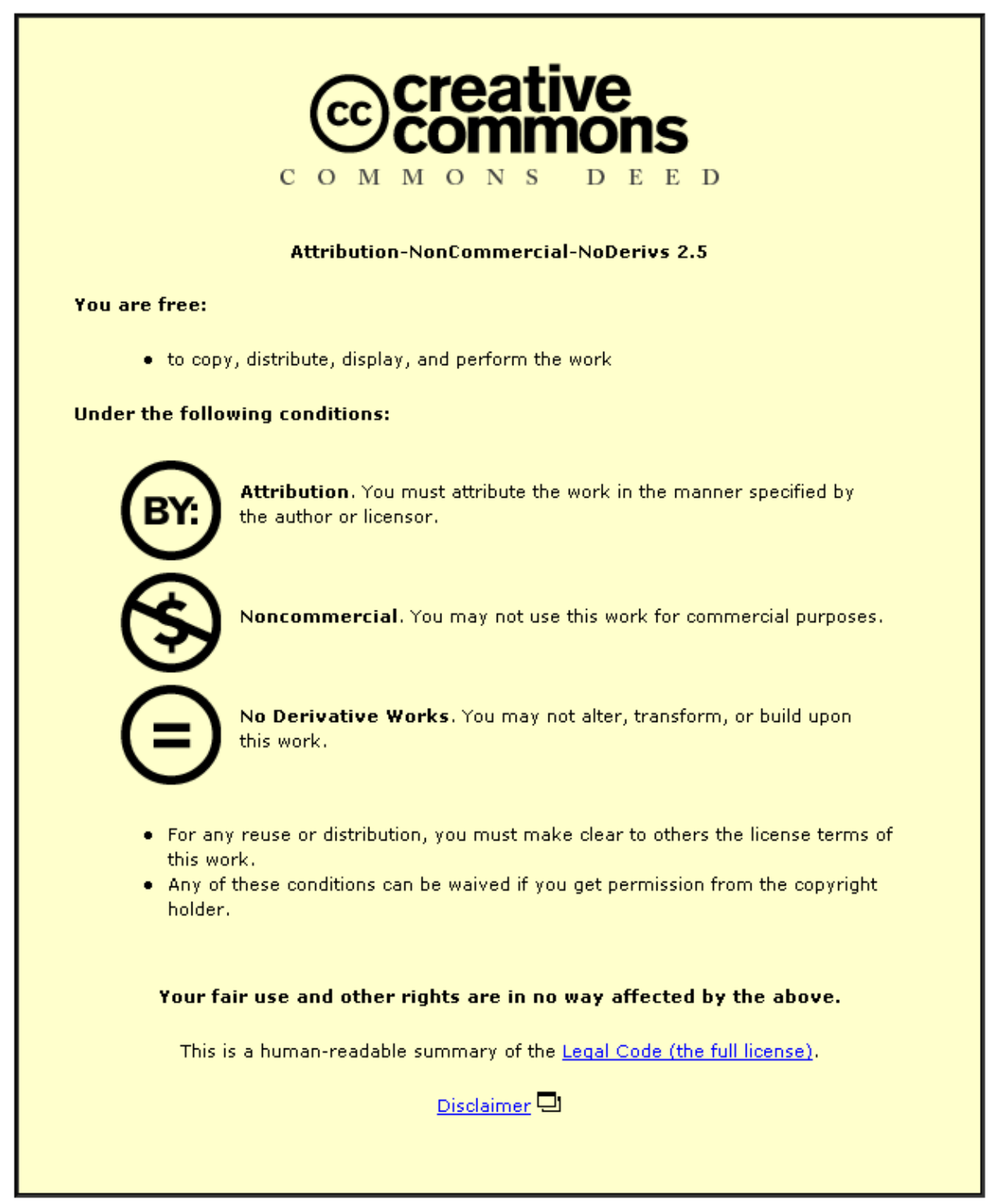

For the full text of this licence, please go to: http://creativecommons.org/licenses/by-nc-nd/2.5/ 


\title{
Hospital Resilience to Natural Hazards: Classification and Performance of Utilities
}

\author{
Nebi Achour ${ }^{1)}$, Masakatsu Miyajima ${ }^{2)}$, Federica Pascale ${ }^{1)}$ and Andrew Price ${ }^{1)}$ \\ 1) School of Civil and Building Engineering, Loughborough University, UK N.Achour@lboro.ac.uk \\ 2) Graduate School of Natural Science and Technology, Kanazawa University, Japan
}

\begin{abstract}
Purpose: This study aims to: (1) explore major and potential challenges facing healthcare facilities operation specifically those related to utility supplies; and (2) quantify the impact of utility supplies interruption on the operation of healthcare facilities through the development of an estimation model.
\end{abstract}

Design/methodology/approach: A pluralistic qualitative and quantitative research approach benefiting from an online computer program that applies the Discriminant Function Analysis approach. Information was collected from 66 hospitals following three major earthquakes that struck north-east Japan in 2003.

Findings: Analysis demonstrated that healthcare utilities face three major challenges: vulnerability of infrastructure to natural hazards, low performance of alternative sources; and lack of consideration of healthcare utility supplies in resilience codes and legislations. The study also proposed a method to estimate the impact of utility interruption of healthcare facilities. A model has been developed for the case study hospitals in Northern Japan following three major earthquakes in 2003.

Practical implications: The findings are expected to raise the awareness of the critical role utilities play for the operation of healthcare facilities which will potentially lead to upgrading resilience codes and legislations. The findings are also expected to pool the literature with more information about the resilience of healthcare utility publications.

Originality/value: The topic and issues discussed in this research are original based on authors' investigations following three major earthquakes that took place in north-east Japan. The study followed a statistical approach in addressing the inter-relationship between the utility systems post disasters to develop an innovative unique index to predict the impact of utility shortage on healthcare.

Keywords: healthcare facility, utility, electric power, multi-hazards, natural hazards, earthquake, Japan

\section{INTRODUCTION}

\subsection{Overview}

Recent publications suggest an increase in the number of natural hazards (www.emdat.be) and their associated disruptions (Michel-Kerjan, 2011). Earthquakes, floods, landslides, typhoons and other hazards affect many countries and regions around the world. However, the impact tends to be more significant in countries where there is lack of preparedness, large populations and fragile infrastructure, including healthcare. This has encouraged international organisations such as the World Health Organisation (WHO) and the United Nations International Strategy for Disaster Reduction (UNISDR) to organise campaigns and events, such as 'Hospitals Safe from Disasters' global campaign (2008-2009), with the aim to raise awareness and attract attention to protect healthcare facilities from natural hazards. The campaign has been followed by 'Resilient Cities' (2010-2015) aiming to improve the resilience (i.e. robustness, strength and ability to recover from disruptions) of city systems as part of sustainable development.

Healthcare facilities are one of the most complicated and critical facilities in any country. They are a key provider of health services as they monitor the wellbeing of society and prevent potential outbreaks. They also play an important role in the local economy, as people from 
different disciplines, backgrounds and abilities are required to administrate. In addition various suppliers, businesses, transport networks (both public and private) are necessary to connect it with external systems. Hospitals are also of particular importance as they are central to dealing with the large number of injuries typically associated with large-scale disasters (Achour and Price, 2010). Healthcare facilities are a combination of two main factors, physical and social. The physical factor was referred to in the Pan America Health Organization (PAHO, 2000) classification as 'structural' and 'non-structural' components. It includes elements such as beams, columns, equipment and utilities. The social factor is often referred to as 'functional' or 'operational' components such as human resources, planning and management processes. In this study, a similar classification has been adopted with slight modification: architectural elements (e.g. doors, windows and separation walls) will be considered as part of the structural category instead of the non-structural category and will be referred to in this paper as 'structural and architectural' components. The non-structural category will include mechanical and electrical systems such as utilities and equipment and will be referred to as 'critical systems and equipment'.

\subsection{Need for more utility resilience research}

There has been a substantial amount of work conducted in the field of healthcare resilience. However, most of it has been dedicated to structural and functional performance. A major proportion of this work has been allocated to reporting the cause of structural damage and fragility such as in Mehani et al. (2011) and Wilkinson et al. (2012), and upgrading structural performance such as in Nuti and Vanzi (1998). Considerable effort has also been directed towards crisis management (Mostafa et al., 2004), staff attendance in disasters (Senpinar-Brunner et al., 2009), preventive strategies (Peek-Asa et al., 1998), risks and opportunities evaluation (Loosemore et al., 2011), logistic management during disasters (VanVactor, 2011) and capacity improvement (Ukai, 1996). In recent years, the frequency of utility resilience publications seems to be increasing. For example, in recent publications, Myrtle et al. (2005) classified non-structural systems in hospitals following a combination of system and empirical approaches, and Hiete et al. (2011) investigated the impact of power outage on hospitals in Germany using a qualitative and empirical research approach. Although, this is a good indication that the resilience of hospital utility system is being the focus of many researchers, more research is needed to pool the literature resources with more information that will enhance the resilience of healthcare utility systems specifically in terms of: identifying challenges facing healthcare utilities, and the impact utility's interruption could have on the continuity of healthcare.

The impact of utility failure is relatively comparable to structural failure in terms of the continuity of healthcare service due to external and, or internal utility system damage. The Applied Technology Council (ATC, 2008) recognised this problem stating that the lack of protection of building contents in resilience codes can pose an additional risk to safety and continuity of operations after disasters. There is a significant number of case studies showing the impact of utility failure, which varied between inoperability of medical services and coordination with outside (Kirsch et al., 2010, DH, 2008, Peters, 1996) and evacuation of hospital buildings (Italie and Marchione, 2012, Shinozuka et al., 1995). More case study problems experienced in hospitals due to interruption of utility supplies have been presented in Table 1. These problems have motivated organisations such as the Federal Emergency Management Agency (www.fema.gov) and Geohazards International (www.geohaz.org) to produce guiding documents (e.g. Design Guide for Improving Hospital Safety in Earthquakes, Floods and High Winds (FEMA, 2007) and Reducing Earthquake Risk in Hospitals from 
Equipment, Contents, Architectural Elements and Building Utility Systems (Rodgers et al., 2009)) to help reduce risks associated with the failure of utilities. Hence, it is important to better understand these vital components and how they affect the continuity of medical services. This study is a continuation of the analysis started in Achour et al. (2011), which focused on structural performance. It aims to: (1) explore major and potential challenges facing healthcare facilities operation specifically those related to utility supplies; and (2) quantify the impact of utility supplies interruption on the operation of healthcare facilities through the development of an estimation model.

Table 1: Sample of utility failure impact on hospitals

\begin{tabular}{|c|c|c|c|c|}
\hline Hospital & Hazard & Problem & Consequence & Source \\
\hline NYU Hospital & Hurricane & Loss of electric power & $\begin{array}{l}\text { Evacuation of } 200 \\
\text { patients }\end{array}$ & $\begin{array}{l}\text { (Italie and } \\
\text { Marchione, 2012) }\end{array}$ \\
\hline $\begin{array}{l}\text { Group of hospitals } \\
\text { in Chile }\end{array}$ & Earthquake & $\begin{array}{l}\text { Loss of power and insufficiency } \\
\text { of backup power; interruption of } \\
\text { telecommunication systems; } \\
\text { loss of municipal water }\end{array}$ & $\begin{array}{l}\text { Inoperability of medical } \\
\text { services, coordination } \\
\text { with the outside }\end{array}$ & $\begin{array}{l}\text { (Kirsch et al., } \\
\text { 2010) }\end{array}$ \\
\hline $\begin{array}{l}\text { Gloucestershire } \\
\text { Hospital (UK) }\end{array}$ & Flood & Water contamination & $\begin{array}{l}\text { Inoperability of medical } \\
\text { services and cease of } \\
\text { activities }\end{array}$ & $(\mathrm{DH}, 2008)$ \\
\hline $\begin{array}{l}\text { Christian and } \\
\text { Shiu-Tuan } \\
\text { hospitals }\end{array}$ & Earthquake & Damage to fuel system & Blackout & $\begin{array}{l}\text { (Lee and Loh, } \\
\text { 2000) }\end{array}$ \\
\hline $\begin{array}{l}\text { Kobe University } \\
\text { Medical College } \\
\text { (Japan) }\end{array}$ & Earthquake & $\begin{array}{l}\text { Damage to high raised water } \\
\text { tank }\end{array}$ & $\begin{array}{l}\text { Flooding, Blackout and } \\
\text { evacuation of the } \\
\text { facility }\end{array}$ & $\begin{array}{l}\text { (Shinozuka et al., } \\
\text { 1995) }\end{array}$ \\
\hline $\begin{array}{l}\text { Group of hospitals } \\
\text { in Iowa (USA) }\end{array}$ & Flood & Water loss & $\begin{array}{l}\text { Nearly all phases of } \\
\text { patient care and facility } \\
\text { operation were affected }\end{array}$ & (Peters, 1996) \\
\hline
\end{tabular}

\section{LITERATURE REVIEW: CHALLENGES FACING UTILITY SUPPLIES}

\subsection{Increasing hazards and critical infrastructure vulnerability}

Recent research outcomes suggest that the number of natural hazards, both environmental and geo-physical, will increase due to the effect of global warming (Sauber and Ruppert, 2008, Hetzel and Hampel, 2006). Although, the connection between geo-physical hazards and global warming is still debatable, there is an urgent need to improve the resilience of healthcare infrastructure to cope with environmental, geological and hydrometeorological hazards as they have increased over 20 fold since the 1940s (www.emdat.be) and have the potential to cause complex disasters that occur simultaneously or separately. Over the last few years, there were several highly disruptive natural events that demonstrate the complexity and diversity of impact associated with natural hazards. Disasters "are not always singular or isolated events...they can occur in complex combinations and, or rapid succession” (EEA, 2003), as demonstrated by the experience of many countries such as China in 2008 where the Sichuan Earthquake was followed by floods and landslides magnifying the amount of disruption caused by the earthquake.

Infrastructure failures can be driven by the intensity of disasters or also by vulnerability. Many countries' infrastructure vulnerability is due to lack of expenditure, and/or the increasing number and severity of climate change driven natural hazards. For example, the World 
Economic Forum's annual Global Competitiveness Report ranked the United Kingdom (UK) "mid-table compared to the rest of the world in terms of its basic infrastructure networks" (Orr, 2010) and the Institution of Civil Engineers' (ICE) State of the Nation: Infrastructure report (ICE, 2010) highlighted "significant deficiencies in these critical national assets", in part resulting from lack of integration and collaboration between sectors, decreasing resilience, lack of sustainability, impact of significant cuts and failure to take account of future needs. In winter, the UK consumes approximately 60 gigawatts of electric power, most of which are generated by 30 large power stations (ICE, 2010). Many of these power stations are located in vulnerable areas such as the Dungeness power plant, which is built few meters above sea level on an "unstable geological formation" (Paskal, 2009), and the hundreds of power substations and water treatment plants that have been built in floodplain areas (BBC, 2008). Some of this infrastructure has been very close to failure during recent events: for example, the Ulley reservoir (built in 1871) and the Walham substation during the 2007 summer floods.

\subsection{Low performance of backups}

International organisations such as the World Health Organisation (WHO) and PAHO recommended that healthcare facilities have alternative suppliers and duplicate items to provide a certain level of independence from external supply networks (PAHO, 2000). Consequently, many hospitals have been equipped with alternative supply systems, which increased their resilience and secured the continuity of healthcare. There are many alternative sources, but most used are Uninterruptible Power Supply (UPS) systems and power generators. UPS systems have been used in many facilities around the world (e.g. in Milton Keynes General Hospital in the UK and Matto Public Hospital in Japan). They are charged with commercial power or fuel power generators (Shinozuka et al., 1995); however, experience has demonstrated that commercial power automatically shuts down in earthquakes for safety reasons (e.g. Tomato-Atsuma power station, Japan) or as a result of network damage which underlines the risk of power interruption. The performance of power generators has been a major issue in hospitals for many decades: Jones and Mar (1945) stated that generators "operating troubles were due largely to unsatisfactory cooling”. The Kobe University Medical College and Hyogo Medical Center could not use their power generators for fear of overheating as the cooling system depended on water supply which was damaged in both facilities following the 1995 Japanese Hyogo Nambu Earthquake - also known as Kobe Earthquake (Shinozuka et al., 1995); and the Christian and Shiu-Tuan hospitals lost their electric power due to damage to fuel systems (Lee and Loh, 2000).

\subsection{Integration in resilience codes and legislations}

Utilities play a considerable role in the continuity of medical services such as supplying equipment, guarantee continuity of care, especially in critical areas, maintaining the indoor environmental quality, and connecting the facility with the outside. However, this role is frequently overlooked in many resilience codes and legislations designed to ensure the minimum required performance of the built environment or infrastructural component, where the focus is more on protecting structural components, as they cause direct threat to human life in case of hazards rather than critical systems such as utilities. A review of five international resilience codes, legislations and guidelines (see Table 4) led to the conclusion that there is a contrast between countries' approaches in addressing the resilience of healthcare utilities: whilst the EuroCode 8 (European seismic design code), RPA 99 (Algerian seismic design code) and Iranian seismic design codes do not seem to pay attention to utilities, legislations in the UK and California tend to be more comprehensive. The UK Civil Contingency Act 2004 provides a comprehensive and generic set of legislations under which 
the Health Building Notes - HBNs - (DH, 2007a) and Health Technical Memoranda - HTMs (DH, 2007b) provide a set of suggestions and recommendations to support healthcare facilities improving their resilience. Californian authorities, however, developed the Senate Bill (SB) 1953 specifically for hospitals to highlight the importance of its medical facilities as many of them suffered significant damage in previous earthquakes.

Table 4 - Resilience codes, legislations and guidelines

\begin{tabular}{|c|c|c|c|}
\hline Code/legislation & $\begin{array}{c}\text { Structural and } \\
\text { Architectural components }\end{array}$ & Equipment and Utilities & Comments \\
\hline SB 1953 (California) & $\sqrt{ }$ & $\sqrt{ }$ & Specific for hospitals \\
\hline $\begin{array}{c}\text { Iranian 3 } \\
\text { 2007 Edition }\end{array}$ & $\sqrt{ }$ & - & Generic \\
\hline $\begin{array}{c}\text { RPA 99 V2003 } \\
\text { (Algeria) }\end{array}$ & $\sqrt{ }$ & - & Generic \\
\hline $\begin{array}{c}\text { EuroCode 8 (French } \\
\text { Edition) }\end{array}$ & $\sqrt{ }$ & $\sqrt{ }$ \\
\hline $\begin{array}{c}\text { HBNs and HTMs } \\
\text { (UK) }\end{array}$ & - & Specific for hospitals \\
\hline
\end{tabular}

\section{RESEARCH DESIGN}

The research reported in the paper adopted a pluralistic qualitative and quantitative approach. Comprehensive literature review, including reconnaissance reports, research papers and official documents were reviewed to identify lessons learnt from previous experience and challenges facing future healthcare services. The findings were complemented by the findings of field investigations (questionnaire survey) to develop a tangible measure for the impact of utility failure on the performance of hospitals.

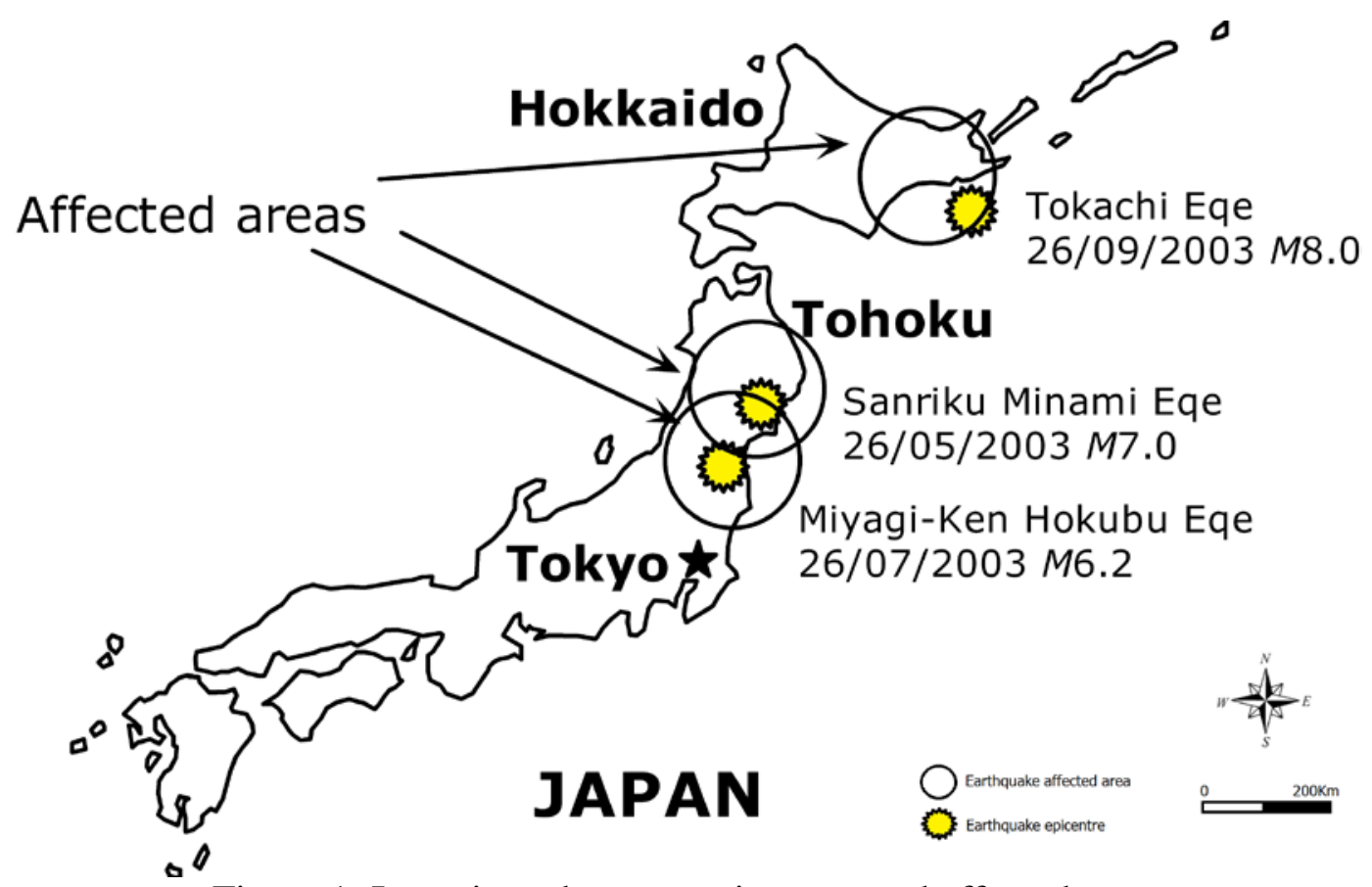

Figure 1: Investigated events epicentres and affected areas (affected areas are not to scale) 
The investigations were conducted during December 2003 in the Japanese Tohoku and Hokkaido areas where three major earthquakes struck in May, July and September of the same year. Figure 1 illustrates the locations of surveys and Table 2 summaries earthquakes' damage. In November 2003, questionnaires were sent, by postal mail, to 120 hospitals. Responders where given one month to respond using a stamped-addressed-envelope. Responses were received from 66 facilities located in the affected areas. Each responding hospital was assigned an identifying code H1 to H66 (Table 3).

Table 2: Characteristics and impact of the events

\begin{tabular}{|l|l|l|l|l|l|}
\hline \multicolumn{1}{|c|}{ Earthquake } & Date & \multicolumn{1}{c|}{$\begin{array}{c}\text { Local } \\
\text { Time }\end{array}$} & $\begin{array}{l}\text { Magnitude } \\
\text { (JMA scale) }\end{array}$ & $\begin{array}{l}\text { Hypocenter } \\
(\mathrm{km})\end{array}$ & \multicolumn{1}{c|}{ Observations } \\
\hline $\begin{array}{l}\text { Miyagi-ken } \\
\text { Sanriku- Minami } \\
\text { Earthquake }\end{array}$ & $\begin{array}{l}26 \\
\text { May } \\
2003\end{array}$ & $6: 24$ p.m. & $M 7.0$ & 60 & $\begin{array}{l}\text { Buildings suffered various levels of damage. } \\
174 \text { people injured. Health care facilities } \\
\text { suffered structural and lifeline damage. }\end{array}$ \\
\hline $\begin{array}{l}\text { Miyagi-ken } \\
\begin{array}{l}\text { Hokubu } \\
\text { Earthquake }\end{array}\end{array}$ & $\begin{array}{l}26 \mathrm{Jul} \\
2003\end{array}$ & $7: 13$ a.m. & $M 6.2$ & 12 & $\begin{array}{l}11,341 \text { houses and buildings were damaged. } \\
14,000 \text { families were affected by damage to } \\
\text { water supply network. } \\
\text { 638 people injured and were treated in 17 } \\
\text { hospitals. } \\
\text { Two hospitals suffered very severe damage to } \\
\text { their structure as well as their lifelines. }\end{array}$ \\
\hline $\begin{array}{l}\text { Tokachi-Oki } \\
\text { Earthquake }\end{array}$ & $\begin{array}{l}26 \text { Sep } \\
2003\end{array}$ & $4: 50$ a.m. & $M 8.0$ & 40 & $\begin{array}{l}\text { No deaths ensued but 755 people were injured. } \\
\text { Damage to lifelines was very evident in the } \\
\text { form of a widespread blackout. }\end{array}$ \\
\hline
\end{tabular}

Table 3: Interruption and performance index of hospitals

\begin{tabular}{|c|c|c|c|c|c|c|c|c|c|c|c|}
\hline \multirow{2}{*}{ Hospital } & \multicolumn{6}{|c|}{ Utility duration of interruption (hours) } & \multicolumn{3}{|c|}{ Performance Index- $y$} & \multicolumn{2}{|c|}{ Comments } \\
\hline & $x_{1}$ & $x_{2}$ & $x_{3}$ & $x_{4}$ & $x_{5}$ & $x_{6}$ & Real & Calc. & Est. & $E q^{\underline{e}}$ & Results \\
\hline $\mathrm{H} 2$ & 0.1 & 0 & 0 & 0 & 0.1 & 0.1 & 0 & 0.118 & 0 & Hokkaido & \\
\hline H3 & 1 & 0 & 0 & 0 & 0 & 0 & 0 & -1.238 & 1 & Hokkaido & False \\
\hline H7 & 0.2 & 0 & 0 & 0 & 0 & 0 & 0 & -0.149 & 1 & Hokkaido & False \\
\hline H9 & 0 & 0 & 0 & 1.5 & 1.5 & 1.5 & 0 & 1.993 & 0 & Hokkaido & \\
\hline H14 & 0 & 0 & 0 & 0 & 6 & 0 & 0 & 0.378 & 0 & Hokkaido & \\
\hline H21 & 0 & 0 & 0 & 0 & 2 & 0 & 1 & 0.208 & 0 & Hokkaido & False \\
\hline H22 & 1 & 0 & 0 & 0 & 0 & 0 & 0 & -1.238 & 1 & Miyagi-H & False \\
\hline H26 & 0 & 0 & 0 & 0 & 1 & 0 & 0 & 0.166 & 0 & Miyagi-S & \\
\hline H28 & 0 & 0 & 0 & 0 & 3 & 0 & 0 & 0.251 & 0 & Miyagi-S & \\
\hline H30 & 0 & 0 & 0 & 0 & 3 & 0 & 0 & 0.251 & 0 & Miyagi-S & \\
\hline H36 & 0 & 0 & 0 & 0.5 & 0.5 & 0.5 & 0 & 0.746 & 0 & Miyagi-H & \\
\hline H37 & 0 & 0 & 0.7 & 3 & 3 & 0 & 0 & 1.491 & 0 & Miyagi-S & \\
\hline H38 & 0 & 0 & 0 & 3 & 3 & 0 & 0 & 0.050 & 0 & Miyagi-S & \\
\hline H39 & 0 & 0 & 0 & 0.1 & 0.1 & 0 & 1 & 0.121 & 0 & Miyagi-N/A & False \\
\hline H41 & 0 & 2 & 0 & 0 & 0 & 0 & 0 & 0.448 & 0 & Miyagi-H & \\
\hline $\mathrm{H} 42$ & 0 & 0 & 0 & 8 & 8 & 0 & 0 & -0.072 & 1 & Miyagi-H & False \\
\hline H43 & 0 & 0 & 0 & 1 & 1 & 0 & 0 & 0.099 & 0 & Miyagi-S & \\
\hline $\mathrm{H} 45$ & 0 & 0 & 0 & 1 & 1 & 1 & 0 & 1.369 & 0 & Miyagi-H & \\
\hline H53 & 0 & 0 & 0 & 1 & 1 & 1 & 0 & 1.369 & 0 & Miyagi-N/A & \\
\hline H54 & 0 & 0 & 0 & 3 & 0 & 0 & 0 & -0.078 & 1 & Miyagi-N/A & False \\
\hline H57 & 0 & 0 & 0 & 3 & 3 & 0 & 1 & 0.050 & 0 & Miyagi-S & False \\
\hline H61 & 1.5 & 0 & 0 & 1 & 1 & 0 & 1 & -1.943 & 1 & Miyagi-H & \\
\hline H62 & 0 & 0 & 0 & 0 & 1 & 0 & 0 & 0.166 & 0 & Miyagi-S & \\
\hline H65 & 0 & 10 & 0 & 2 & 2 & 0 & 0 & 1.670 & 0 & Miyagi-S & \\
\hline
\end{tabular}

Hokkaido: Tokachi-Oki Earthquake, Miyagi-H: Miyagi-ken Hokubu Earthquake,

Miyagi-S: Miyagi-ken Sanriku-Minami Earthquake; Miyagi-N/A: the response is not provided Miyagi-H or Miyagi-S.

The questionnaire comprised of 45 questions divided into seven sections: Structural Damage, Injury to Personnel, Utility Damage, Medical Equipment Damage, Relief Activities, Crisis Management and General Information. Questions were designed based on a preliminary site 
visits and aimed to collect the level of structural damage, stability of equipment, duration of utility interruption, impact of damage on healthcare duties, presence of crisis management courses and manuals, food and drug supplies.

The 66 responses were screened based on: complete information provided in the response sheet; importance of the facility for post-earthquake emergency provision; and level of structural damage. Facilities such as dental clinics and those moderately to heavily damaged facilities were not considered in this study in order to ensure that utility interruption was not caused by structural and/or architectural elements and that facilities inoperability was due solely to utility disruptions. Consequently, 24 cases were found suitable for this study, see Table 3.

Questionnaire survey data were analysed further according to 'Theory of Estimation' using an online computer program (Aoki, 2006) that applies the 'Discriminant Function Analysis' approach to determine which variables discriminate between the two naturally occurring groups: unaffected (Group 0) and affected (Group 1). The method involved combining all variables, affecting the operation of the facilities, into one mathematical equation to: (1) estimate whether healthcare has been affected or unaffected; and (2) classify these variables according to their greater impact on the operation of the healthcare facility.

\section{IMPACT OF UTILITY INTERRUPTION ON HEALTHCARE: CASE STUDY}

Findings demonstrate that, despite the limited number of case studies, the collected data is important as $45 \%$ of the respondents accepted earthquake-related injuries. Findings also demonstrated that most hospitals (68\%) had sound resilience strategies, including the provision of emergency manuals (covering hazards such as fire, earthquakes, floods, snow and tsunamis), were supported annually with one to two lectures in 53\% of the facilities and trainings (in 88\%), and were equipped with alternative sources for critical utilities such as electricity and water. These measures supported the hospitals to remain operational. However, some facilities could not operate properly due to inappropriate equipment: for example, the Ishimaki Night Emergency Center (H51) had to halt the X-ray service due to insufficient power supply. Respondents highlighted that interdependency between utility systems was a problem for continued operation: the Tohoku Koseinenkin Hospital (H29) extracts water from boreholes which then has to be filtered electrically before use, the shortage of electric power resulted in a lack of water supply. Many hospitals' staff reported that they had to redial many times to get connected which indicates that there were problems with telephone network suppliers. Hospitals such as the Fukaya (H27) and Kashimadai (H59), which were eliminated from this study, suffered damage to their structures and internal pipeline networks, and interruption of commercial power causing patients to be transferred to other facilities.

A total of six utilities were identified for analysis due to their common usage in Japanese healthcare facilities. Each of the utilities was illustrated with a mathematical variable $\left(x_{i}\right)$, namely: electricity $\left(x_{1}\right)$, gas supply $\left(x_{2}\right)$, water supply $\left(x_{3}\right)$, landline telecommunication $\left(x_{4}\right)$, mobile phone $\left(x_{5}\right)$ and Personal Handy-phone System (PHS phone) $\left(x_{6}\right)$. Data was divided into two groups identified according to the response to the question: 'Did utility malfunction have an impact on your task?' A 'Yes' answer, represented by ' $y=1$ ', implies the shortage of utility affected the hospital operation, and a ' $N o$ ' answer, represented by ' $y=0$ ', implies the shortage of utility did not affect the hospital operation. 


$$
y=-1.36 x_{1}+0.163 x_{2}+2.059 x_{3}-0.067 x_{4}+0.043 x_{5}+1.27 x_{6}+0.123
$$

Equation 1 was generated in which each variable was weighted automatically, according to the Estimation Theory. The equation was used to estimate the effect of utility shortage on healthcare by calculating value ' $y$ ' for each facility. A positive value of $y$ implies unaffected healthcare (considered as $y=0$ ), whilst a negative value implies affected healthcare (considered as $y=1$ ). Table 3 illustrates that in $67 \%$ of cases, the prediction of functionality agreed with the actual facility performance. The cases where estimation was not accurate are marked with 'False' in the 'Comments' column of Table 3.

The standardized coefficient of each variable was calculated to identify the most influential variable, which has the highest absolute value. According to Table 5, $x_{1}$ is the most important variable (standardized coefficient $=0.534$ ), thus the most important utility for the operation of these facilities is electric power. This result concurs with many research findings such as in Myrtle et al. (2005) where electrical system was classified as the second most important utility after the pipeline system (e.g. gas and water) in hospitals, and in DeDeRHECC (2010) where power was classified as the most important due to the impact power shortage could have on medical services.

Table 5: Classification of utilities and standardised coefficients

\begin{tabular}{|c|c|c|c|}
\hline Degree of importance & Variable & Utility system & Absolute value of standard Coefficient \\
\hline 1 & $x_{1}$ & Electricity & 0.534 \\
2 & $x_{6}$ & PHS phone & 0.506 \\
3 & $x_{2}$ & Gas & 0.328 \\
4 & $x_{3}$ & Water & 0.288 \\
5 & $x_{4}$ & Tel. Landline & 0.120 \\
6 & $x_{5}$ & Mobile phone & 0.083 \\
\hline
\end{tabular}

\section{DISCUSSION AND DIRECTION OF CRITICAL RESEARCH}

\subsection{Need for a comprehensive strategy for healthcare utility resilience:}

One of the major characteristics of healthcare facilities is that they are highly dependent systems. They depend on many systems such as critical infrastructure to operate (e.g. electric power, water and telecommunication). In order to reduce this dependency and increase resilience, many healthcare facilities are equipped with alternative sources, which are expected to replace main sources in emergency situations. However, previous experience demonstrates that these alternative sources are not always reliable. The challenge is therefore what needs to be done to ensure the continuity of utility supplies? The study identified three major directions that could potentially reduce the vulnerability of healthcare utility supply if they are adopted in a comprehensive strategy for healthcare utility resilience. These are: (1) improving the resilience of utility infrastructure to natural hazards; (2) improve performance of alternative sources; and (3) ensure that healthcare utility supplies are well covered by resilience codes and legislations.

a- Resilience of utility infrastructure:

The improvement of infrastructure is a major challenge in many countries as this requires significant financial resources and recognisable risks. However, the on-going financial crisis will make this a major challenge and perhaps will require more efficient and effective strategies. On the risk recognition side, countries which historically are classified as 'safe from disasters', such as the UK, are in need more than ever to improve their infrastructure resilience 
and 'expect what is not expected'. The conventional methods of hazard prediction are perhaps difficult to accurately predict future natural hazards as they are based on historical data. However due to the presumption that these countries are safe from disasters, most of these historical data do not necessarily exist. The experience of hazard-exposed-countries such as Japan and China thus could be useful in identifying potential scenarios.

\section{$b$ - Performance of alternative resources:}

The study findings point to there being two elements that affect the performance of alternative sources: mechanical failure and dependency on critical infrastructure (i.e. main supply). There are limited options to avoid mechanical failure these include regular maintenance and testing and adoption of less dependent systems such as air-cooled power generators. This indicates the need to investigate more reliable and independent techniques. For example, renewable energy could be examined further to find out whether the energy delivered could meet with the demand of healthcare facilities in emergency times.

c-Integration of utility in resilience codes:

The contrast between countries in protecting healthcare utility supplies demonstrates that there is lack of understanding of the critical role utilities play in the continuity of healthcare in emergencies. Authorities need to work harder to develop minimum requirements to protect healthcare utilities especially with the increasing risks disasters and potential of more demand on healthcare.

\subsection{Quantification of the impact of utility supplies interruption on healthcare:}

The approach adopted in quantifying the impact of utilities on healthcare is a major contribution of this study and has the potential to be applied to different settings and situations (e.g. flood and typhoon). The equation provides an estimation of this impact and enables the classification of utility systems according to their effect on the overall impact. The identification of electric power being at the forefront of the most influential systems was expected due to previous work of Myrtle et al. (2005) and DeDeRHECC (2010) publication. However, whilst the latters followed a system and empirical approaches to identify the most important utility system, this study followed a statistical approach that complements these approaches to introduce a new way to quantify the impact of interruption on healthcare.

\subsection{Research limitation:}

During the data analysis process, a few research limitations have been identified. These are mainly driven by the limitation of data which affected the final results in terms of applicability and accuracy. The equation was developed based on data collected from facilities located in the Japanese Tohoku and Hokkaido areas following three major earthquakes. This indicates that, in its current form, it is true only for the facilities shown in the study sample. The equation also does not take into consideration the existence of, and effect alternative supply sources have on the operability of healthcare facilities, which explains its accuracy to be $67 \%$. These limitations will be addressed in future research activities.

\section{CONCLUSION}

The importance of healthcare infrastructure lies with the vital service they provide at all times. However, their complexity and dependency on external infrastructure make them vulnerable. Experience demonstrated that infrastructure have been affected by the increasing number of hazards due to the changing climate. In order to reduce this vulnerability many healthcare facilities were equipped with alternative sources with the view to provide necessary supplies 
when needed. However, this also was not always possible as these sources did not perform as were expected due to mechanical failure or their dependency on other supplies. This indicates a need to investigate more reliable and independent systems such as renewable energy.

Developing the right strategy could be the most significant step toward the resilience of healthcare facilities. This strategy is three fold:

- Improving the resilience of utility infrastructure to natural hazards;

- Improving performance of alternative sources; and

- Ensuring that healthcare utility supplies are well covered by resilience codes and legislations.

The study proposed a method to quantify the impact of utility supplies' interruption on the continuity of healthcare through the development of an equation, in which each of its variables represents a utility. The equation also allows the ranking of utilities according to their ability to affect the overall performance of the facility. The equation successfully estimates the inoperability of $67 \%$ of the study sample. Future research work will focus on improving this ratio further and on developing an equation that could be used in a wider setting and situations.

\section{Acknowledgment}

The authors want to express their sincere thanks to Professor Masaru Kitaura and Dr Akira Murata of Kanazawa University (Japan) and Prof Masaho Yoshida of Fukui National College of Technology (Japan) for their help in collecting the data for this paper. Special thanks are also to the staff of hospitals for their time spent to provide us with the data required for this study. Sincere acknowledgments are to the Japanese Ministry of Education, Culture, Sports, Science and Technology (MEXT) and to the Engineering and Physical Sciences Research Council (EPSRC, UK) for funding this research work.

\section{References}

Achour, N., Miyajima, M., Kitaura, M. \& Price, A. (2011), "Earthquake Induced Structural and Nonstructural Damage in Hospitals", Earthquake Spectra, Vol. 27, No. 3, pp. 617-634.

Achour, N. \& Price, A. D. F. (2010), "Resilience Strategies of Healthcare Facilities: Present and Future", International Journal of Disaster Resilience in the Built Environment, Vol. 1, No. 3, pp. 264-276.

Aoki, S. (2006), "Two Crowds' Discriminant Function Analysis", Gunma University, available at: http://aoki2.si.gunma-u.ac.jp/JavaScript/disc.html (accessed 28 March 2006).

ATC (2008), Reducing the Risks of Nonstructural Earthquake Damage: State-of-theArt and Practice Report. Redwood City, California: Applied Technology Council (ATC).

BBC (2008), "Flood risk fear over key UK sites ", available at: http://news.bbc.co.uk/1/hi/uk_politics/7386383.stm (accessed 24 June 2013).

DeDeRHECC (2010), Notes of the Second Sounding Panel October 2010. Cambridge: University of Cambridge, Design and Delivery of Robust Hospital Environments in a Changing Climate (DeDeRHECC).

DH (2007a), HBN 00-07: Resilience Planning for Healthcare Estates. In: DEPARTMENT OF HEALTH (DH) (ed.). TSO.

DH (2007b), Health Technical Memorandum 06-01: Electrical services supply and distribution

(Part A: Design considerations). In: (DH), D. O. H. (ed.). Norwich, UK: The Stationery Office (TSO).

DH (2008), A Report on the lessons learned from the summer 2007 flooding experiences from 
an Estates \& Facilities perspective. Leeds: Department of Health (DH).

EEA (2003), Mapping the impacts of recent natural disasters and technological accidents in Europe. Copenhagen: European Environment Agency (EEA).

FEMA (2007), Design Guide for Improving Hospital Safety in Earthquakes, Floods and High Winds. Risk Management Series. Washington D.C.: Federal Emergency Management Agency (FEMA).

Hetzel, R. \& Hampel, A. (2006), "Long-Term Rates of Faulting Derived from Cosmogenic Nuclides and Short-term Variations caused by Glacial-Interglacial Volume Changes of Glaciers and Lakes", International Journal of Modern Physics B, Vol. 20, No. 3, pp. 261-276.

Hiete, M., Merz, M. \& Schultmann, F. (2011), "Scenario-based impact analysisof a power outage on healthcarefacilities in Germany", International Journal of Disaster Resilience in the Built Environment, Vol. 2, No. 3, pp. 222-244.

ICE (2010), The State of Nation: Infrastructure 2010. London: Institution of Civil Engineers (ICE).

Italie, L. \& Marchione, M. (2012), "NYU Hospital Evacuation: Hurricane Sandy Power Failure Moves More Than 200 Patients ", Huffington Post, available at: http://www.huffingtonpost.com/2012/10/30/nyu-hospital-evacuation-hurricane-sandy nn_2044026.html (accessed 24 June 2013 2013).

Jones, A. M. \& Mar, E. (1945), "The Grid and Independent Generators in Parallel at a Large Hospital", The Hospital Engineer Newsletter, Vol. 1, No. September 1945, pp. 5-9.

Kirsch, T. D., Mitrani-Reiser, J., Bissell, R., Sauer, L. M., Mahoney, M., Holmes, W. T., Cruz, N. S. \& Maza, F. d. l. (2010), "Impact on hospital functions following the 2010 Chilean earthquake", Disaster Medicine and Public Health Preparedness, Vol. 4, No. 2, pp. 122-128.

Lee, G. C. \& Loh, C.-H. (2000), The Chi-Chi Taiwan Earthquake of September 21, 1999: Reconnaissance Report. New York: Multidisciplinary Center for Earthquake Engineering Research (MCEER).

Loosemore, M., Carthey, J., Chandra, V. \& Chand, A. M. (2011), "Climate change risksand opportunities inhospital adaptation", International Journal of Disaster Resilience in the Built Environment, Vol. 2, No. 3, pp. 210-221.

Mehani, Y., Benouar, D., Bechtoula, H. \& Kibboua, A. (2011), "Vulnerability evaluation of the strategic buildings in Algiers (Algeria): a methodology", Natural Hazards, Vol. 59, No. 1, pp. 529-551.

Michel-Kerjan, E. (2011), "Prepare yourself, natural disasters will only get worse", The Washington Post, available at: http://articles.washingtonpost.com/2011-09-15/national/35274771_1_natural-disasters -hurricane-irene-earthquakes (accessed 5 July 2013).

Mostafa, M. M., Sheall, R., Morris, M. \& Ingham, V. (2004), "Strategic preparation for crisis management in hospitals: empirical evidence from Egypt", disaster Prevention and Management, Vol. 13, No. 5, pp. 399-408.

Myrtle, R. C., Masri, S. F., Nigbor, R. L. \& Caffrey, J. P. (2005), "Classification and Prioritization of Essential Systems in Hospitals under Extreme Events", Earthquake Spectra, Vol. 21, No., pp. 779-802.

Nuti, C. \& Vanzi, I. (1998), "Assessment of post-earthquake availability of hospital system and upgrading strategies", Earthquake Engineering \& Structural Dynamics, Vol. 27, No. 12, pp. 1403-1423.

Orr, D. (2010), "ICE report raises concerns over UK infrastructure", The Engineer, available at: 
http://www.theengineer.co.uk/opinion/viewpoint/ice-report-raises-concerns-over-uk-i nfrastructure/1002969.article (accessed 3 February 2011).

PAHO (2000), Principles of Disaster Mitigation in Health Facilities, Pan American Health Organization (PAHO), Washington DC.

Paskal, C. (2009), The vulnerability of energy infrastructure to environmental change. London: Chatham House.

Peek-Asa, C., Kraus, J. F., Bourque, L. B., Vimalachandra, D., Yu, J. \& Abrams, J. (1998), "Fatal and hospitalized injuries resulting from the 1994 Northridge earthquake", International Epidemlological Association, Vol. 27, No., pp. 459-465.

Peters, M. S. (1996), "Hospitals respond to water loss during the Midwest floods of 1993: Preparedness and improvisation", Journal of Emergency Medicine, Vol. 14, No. 3, pp. 345-350.

Rodgers, J., Cedillos, V., Kumar, H., Tobin, L. T. \& Yawitz, K. (2009), Reducing Earthquake Risk in Hospitals from Equipment, Contents, Architectural Elements and Building Utility Systems. New Delhi: Geohazards International and Geohazards Society.

Sauber, J. \& Ruppert, N. (2008), "Rapid ice mass loss: Does it have an influence on earthquake occurrence in southern Alaska?", In: HAEUSSLER, P. J., WESSON, R. \& EKSTROM, G. (eds.) Active Tectonics and Seismic Potential of Alaska, Geophysical Monograph Series, 369-384.

Senpinar-Brunner, N., Eckert, T. \& Wyss, K. (2009), "Acceptance of Public Health Measures by Air Travelers, Switzerland", Emerging Infectious Diseases, Vol. 15, No. 5.

Shinozuka, M., Ballantyne, D., Borcherdt, R., Buckle, I., O'Rourke, T. \& Schiff, A. J. (1995), The Hanshin-Awaji Earthquake of January 17, 1995: Performance of Lifelines. In: SHINOZUKA, M. (ed.). New York: National Center for Earthquake Engineering Research.

Ukai, T. (1996), "Problems of Emergency Medical care at the Time of the Great Hanshin-Awaji Earthquake", Annals of Burns and Fire Disasters, Vol. IX, No. 4, pp. 6p.

VanVactor, J. D. (2011), "Cognizant healthcarelogistics management: ensuringresilience during crisis", International Journal of Disaster Resilience in the Built Environment, Vol. 2, No. 3, pp. 245-255.

Wilkinson, S. M., Alarcon, J. E., Mulyani, R., Whittle, J. \& Chian, S. C. (2012), "Observations of damage to buildings from MW 7.6 Padang earthquake of 30 September 2009", Natural Hazards, Vol. 63, No. 2, pp. 521-547. 